Calandria, S. Nuevas figuras jurídicas, antiguas desigualdades de género: la incorporación del infanticidio en el Código Penal. Derecho y Ciencias Sociales. Mayo -Octubre 2021. N 25 .Pgs 23-44. ISSN 1852-2971. Instituto de Cultura Jurídica y Maestría en Sociología Jurídica. Facultad de Ciencias Jurídicas y Sociales. Universidad Nacional de La Plata. Argentina.

\title{
Nuevas figuras jurídicas, antiguas desigualdades de género: la incorporación del infanticidio en el Código Penal
}

New legal forms, old gender inequalities: the incorporation of infanticide in the Criminal Code

Sol Calandria ${ }^{\bullet}$

\section{Resumen}

Este artículo se propone analizar, desde una perspectiva de género, los cambios y continuidades existentes en materia penal con respecto al tratamiento del infanticidio, entre mediados del siglo XIX hasta principios del XX. La incorporación del tipo penal de infanticidio al Código Penal Nacional sancionado en 1886 formó parte de las intenciones del Estado de "modernizar" el sistema penal. Este estudio demuestra que las intenciones de "modernizar" el sistema penal, reflejadas en la incorporación del tipo penal de infanticidio al Código y las modificaciones incorporadas a su figura en la reforma del Código en 1921, no impactaron en materia de género, pues se produjeron continuidades en las representaciones jurídicas de las antiguas desigualdades de género vinculadas al recato sexual y la moralidad femenina, propias del modelo punitivo anterior, que fueron constitutivas de la consolidación misma del Estado nación.

Palabras claves: infanticidio; Código Penal; desigualdades de género; Argentina.

\begin{abstract}
This article examines, from a gender perspective, changes and continuities in criminal law in relation to infanticide, between the mid-nineteenth century and the early twentieth century. The article demonstrates that despite the transformation of the criminal classification of infanticide to the Code and the intentions of State to "modernize" the criminal law -that influenced the coding processes of Latin America-, there were continuities in the legal concepts of the old gender inequalities linked to sexual modesty and female morality, typical of the previous punitive model but, in turn, concomitant with the consolidation of the State.
\end{abstract}

Keywords: infanticide; Criminal Code; gender inequalities; Argentina.

\footnotetext{
- Profesora y Doctora en Historia por la Universidad Nacional de La Plata. Integrante del Centro Interdisciplinario de Investigaciones en Género (CinIG)y del Instituto de Investigaciones en Humanidades y Ciencias Sociales de la Facultad de (IdIHCS), ambos de la Facultad de Humanidades y Ciencias de la Educación de la UNLP. Su investigación se desarrolló en el marco de una beca doctoral del CONICET y en el 2020 obtuvo el premio internacional de investigación "Victoria Kent" para estudios de las mujeres, género y feministas. Desde el año 2015, es docente de la Cátedra Introducción a la Problemática Contemporánea (Departamento de Historia, FaHCE/UNLP). Es directora del programa de extensión: "Educación Popular en Cárceles" (UNLP) Correo: sol.calandria@gmail.com
} 
Calandria, S. Nuevas figuras jurídicas, antiguas desigualdades de género: la incorporación del infanticidio en el Código Penal. Derecho y Ciencias Sociales. Mayo -Octubre 2021. Nº 25 .Pgs 23-44. ISSN 1852-2971. Instituto de Cultura Jurídica y Maestría en Sociología Jurídica. Facultad de Ciencias Jurídicas y Sociales. Universidad Nacional de La Plata. Argentina.

\section{Nuevas figuras jurídicas, antiguas desigualdades de género: la incorporación del infanticidio en el Código Penal}

\section{Introducción}

En América Latina las ideas ilustradas reverberaron en diversos campos dando comienzo a un proceso revolucionario que culminó con la independencia de las monarquías ibéricas. En Argentina, luego de la Revolución de Mayo, los revolucionarios se propusieron terminar con la dominación colonial y dar comienzo a la construcción de un Estado nacional. Uno de sus resultados fue el inicio de un proceso de transición del orden jurídico que fuera acorde con la ideología liberal y que derivó en la codificación del derecho penal. En este proceso de codificación, los juristas argentinos, siguiendo los pasos de los códigos europeos, incorporaron el delito de infanticidio como una figura autónoma del Código Penal.

La incorporación del infanticidio como un delito en sí mismo significó en materia legislativa una ruptura con el período anterior, donde las normativas utilizadas para castigar el asesinato de niños y niñas cometidos por sus progenitoras proponían la pena de muerte. A diferencia de ello, el Código Penal Argentino disminuyó notablemente el castigo. En 1886, el primer Código Penal de la República Argentina incorporó una figura llamada "infanticidio" que contemplaba una pena consideradamente menor para la mujer gestante, pero esta no afectaba a todas por igual, sino únicamente a las mujeres solteras y la hizo extensiva para los padres de éstas, siempre que mediara el móvil del honor. En 1903, este eximente fue ampliado hacia el marido, los hermanos y los hijos de la mujer embarazada. La figura de infanticidio se mantuvo intacta desde este año hasta 1921, cuando una modificación en el Código Penal agregó al estado puerperal y la emoción violenta como circunstancias para que se configure el infanticidio, producto del impacto que las ideas positivistas habían tenido en la esfera penal.

A pesar de que el infanticidio ha despertado el interés de muchos y muchas especialistas tanto en el campo de la historia del derecho, así como también en la historia de las mujeres y los estudios de género (Calandria y Ledesma Prietto, 2018; Calandria, 2018 y 2019; Di Corleto, 2018; Piazzi, 2009; Ruggiero, 1994), éstos direccionaron sus investigaciones más hacia la praxis jurídica que a los cambios normativos que introdujo la codificación penal. Esto puede haberse debido a un creciente interés por el abordaje de las prácticas sociales y las de los agentes de justicia, en detrimento del análisis y problematización de las normas en sí.

En este artículo nos proponemos analizar, desde una perspectiva de género, esos cambios existentes en materia penal con respecto al tratamiento del infanticidio, entre mediados del siglo XIX hasta principios del XX. De esta manera, se demuestra que las intenciones de "modernizar" 
Calandria, S. Nuevas figuras jurídicas, antiguas desigualdades de género: la incorporación del infanticidio en el Código Penal. Derecho y Ciencias Sociales. Mayo -Octubre 2021. N 25 .Pgs 23-44. ISSN 1852-2971. Instituto de Cultura Jurídica y Maestría en Sociología Jurídica. Facultad de Ciencias Jurídicas y Sociales. Universidad Nacional de La Plata. Argentina.

el sistema penal, reflejadas en la incorporación del tipo penal de infanticidio al Código y las modificaciones incorporadas a su figura en la reforma del Código en 1921, no impactaron en materia de género, pues se produjeron continuidades en las representaciones jurídicas de las antiguas desigualdades de género vinculadas al recato sexual y la moralidad femenina, propias del modelo punitivo anterior, que fueron constitutivas de la consolidación misma del Estado nación.

Este estudio considera "lo legal" como parte de un fenómeno social emergente inherente a los conflictos sociales vinculados a un orden jurídico establecido (Bourdieu, 1986) y constituyentes del Estado nación. Esta dimensión de análisis nos permite esclarecer la complejidad de las relaciones sociales y de género que se modelaron a la luz del nuevo orden jurídico. Dicho esto, se advierte que el fenómeno de la codificación puede resultar engañoso, pues su característica inherente es definir, delimitar y ordenar las conductas, es decir, que precisa de la fijación escrita de los conceptos legales. Comprender al infanticidio, no como una categoría legal canónica sino como un concepto dinámico cuyo significado ha sido acuñado y resignificado en tiempo y espacio, resulta útil para observar las diversas tensiones sociales y políticas que subyacieron a su emergencia y en su posterior desarrollo.

Estructuraremos este trabajo en dos apartados. En el primero de ello, analizaremos las fuentes del derecho penal que se utilizaron para castigar al infanticidio en el período posterior a la Revolución de Mayo y que derivaron en la codificación. Para ello, utilizaremos las definiciones de infanticidio en: Las Siete Partidas -elaboradas por Alfonso El Sabio, entre 1252 y 1284- y el Fuero Juzgo -elaborado bajo el reinado de Fernando III en 1241- que rigieron en el Virreinato del Río de La Plata y el resto del territorio colonial iberoamericano; el Diccionario razonado de legislación y jurisprudencia editado por el jurista español Joaquín Escriche, en 1831 y su reedición de 1863; y el Curso de derecho criminal redactado por Carlos Tejedor en 1860. En el segundo apartado, observaremos las rupturas y continuidades en el tratamiento penal del infanticidio, desde que fue incorporado al Código Penal de la Nación Argentina, elaborado por Carlos Tejedor y sancionado en el año 1886.

\section{Castigar un delito, perdonar la maternidad soltera: el infanticidio antes de la codificación}

La Revolución de Mayo y el proceso de la independencia fueron parte de la expresión política de las ideas ilustradas que penetraron progresivamente en diversos campos, entre ellos el derecho. Sin embargo, esto no significó la ruptura inmediata con las instituciones jurídicas existentes durante el período colonial, ni produjo el abandono repentino de la legislación 
Calandria, S. Nuevas figuras jurídicas, antiguas desigualdades de género: la incorporación del infanticidio en el Código Penal. Derecho y Ciencias Sociales. Mayo -Octubre 2021. No 25 .Pgs 23-44. ISSN 1852-2971. Instituto de Cultura Jurídica y Maestría en Sociología Jurídica. Facultad de Ciencias Jurídicas y Sociales. Universidad Nacional de La Plata. Argentina.

vigente, ni de los criterios y valores propios de la tradición jurídica indiana, dentro de la que se encontraba el derecho penal. Durante los 76 años que transcurrieron desde la Revolución de Mayo hasta la sanción del primer Código Penal Nacional en el año 1886, convivieron numerosos principios y normas del derecho castellano-indiano con algunas nuevas leyes y normativas, así como también obras de reconocidos juristas que comenzaron a circular en Argentina y que sirvieron a los jueces para fundamentar sus decisiones. Esto fue posible gracias a la conformación de una cultura jurídica previa a la codificación, que permitió el uso de una multiplicidad de fuentes del derecho a las cuales los jueces acudían para interpretar y elaborar sus sentencias. ${ }^{1}$ Esa convivencia fue posible, según Abelardo Levaggi (2012), debido a un equilibrio que mantenía la observancia del derecho anterior mientras que no se opusiera a los nuevos principios liberales.

Entre las obras utilizadas por los jueces argentinos para castigar el asesinato de un niño recién nacido realizado por sus progenitores, se encontraron textos del derecho indiano, como Las Siete Partidas (1252-1284) y el Fuero Juzgo (1241), así como también importantes libros de juristas liberales, como el Diccionario razonado de legislación y jurisprudencia (1863), de Joaquín Escriche, y el Curso de Derecho Criminal (1860) de Carlos Tejedor. Ahora bien, durante el período comprendido entre 1810 y 1886, año en que fue sancionado el primer Código Penal Nacional, se asistió a un desplazamiento en la praxis jurídica que tendió a utilizar más las dos últimas obras en detrimento de las primeras, aunque en muchas sentencias los magistrados siguieron recurriendo a las Partidas y el Fuero Juzgo cuando el objetivo era endurecer las penas (Calandria, 2018).

Las Partidas no diferenciaron al infanticidio como un tipo especial de homicidio, sino que lo incluyeron en las prácticas definidas para el parricidio, castigadas con la pena capital: "Si el padre matare al hijo o el hijo al padre, o el abuelo al nieto (...) Mandaron los Emperadores y los sabios antiguos que este tal que hizo esta enemiga, que sea acosado públicamente delante de todos y después que lo metan en un saco de cuero, y que encierren con él un can, y un gallo, y una culebra, y un simio, y después de que fuere en

\footnotetext{
${ }^{1}$ En esta cultura jurídica, llamada ius commune, religión y derecho fueron indisociables. Por ello, el asesinato de recién nacidos adquirió una connotación especial en relación con la regulación de la familia y las sexualidad vinculada a dos factores: por un lado, la idea agustiniana de la transmisión del pecado original por medio de cualquier relación carnal; y por toro, la consecuente necesidad del bautismo en la infancia (Lorente Sariñena \& Vallejo, 2012: 107). Estas dos creencias de la tradición cristiana agravaron la connotación que tenía la acción de matar a un recién nacido y progresivamente direccionaron la criminalización hacia las madres solteras (Prósperi, 2016).
} 
Calandria, S. Nuevas figuras jurídicas, antiguas desigualdades de género: la incorporación del infanticidio en el Código Penal. Derecho y Ciencias Sociales. Mayo -Octubre 2021. No 25 .Pgs 23-44. ISSN 1852-2971. Instituto de Cultura Jurídica y Maestría en Sociología Jurídica. Facultad de Ciencias Jurídicas y Sociales. Universidad Nacional de La Plata. Argentina.

el saco con estas cuatro bestias, cosan la boca del saco, y lanzarlos en la mar, o en el río que fuere más cerca de aquel lugar” (Ley XII, Título VIII de la 7ma. Partida).

A diferencia de las Partidas, el Fuero Juzgo realizó una temprana mención especial a la muerte del niño en manos de su propia madre conducta para la que también contemplaba la pena capital como castigo:

"Ninguna cosa non es peor de los padres que non an piadat, é matan sus fiios. [...]

y establezemos que si alguna muier libre ó sierva matar su fiio, pues que en nado,

ó ante que sea nado prender yerbas por abortar, ó en alguna manera lo afogare, el

juez de la tierra, luego que lo sopiere, condémpnela por muerte. E si no la quisier matar, ciéguela" (Escriche, 1863: 857).

Las Partidas y el Fuero Juzgo contemplaron penas muy duras para el asesinato de recién nacidos en manos de sus progenitores y, aunque el segundo hizo una mención a la progenitora, esto fue en dirección a reforzar su responsabilidad. La dureza de la pena se debió a que el castigo, durante el período colonial, tenía una función eminentemente simbólica relacionada con la transgresión al orden divino (Hespanha, 1987). La gravedad de las faltas cometidas por las mujeres imputadas de infanticidio, y su consecuente castigo, derivaban de una doble transgresión al orden celestial y al orden terrenal: pecado y delito. La mujer era pensada idealmente como un ser virtuoso y el infanticidio, por lo tanto, atentaba contra la reproducción del orden natural (Cartelle, 2010; Juliano, 2015). ${ }^{2}$

Sin embargo, la aplicación del derecho en el contexto iberoamericano, al estar influenciada por la religión derivó en una serie de indultos, perdones de parte y otras manifestaciones de clemencia, que se otorgaban cotidianamente (Hespanha, 1993; Agüero, 2008). Por este motivo, a pesar de los duros castigos establecidos en estas obras legales, la pena

\footnotetext{
${ }^{2}$ La Segunda Escolástica de Santo Tomás de Aquino reelaboró la definición del "pecado" y su casuística al reinterpretar la creación, no como un acto único, sino como un continuo en el que el hombre colaboraba con Dios en la tarea de la reproducción y, de esta manera, se convertían en sus socios en la labor creadora. Específicamente, la reinterpretación del Génesis, elaborada por la escolástica, definió los pecados y dividió por grados el tipo de castigo para el transgresor. Esta gradualidad tuvo que ver con la cercanía o distancia al pecado original. Sobre estas premisas, la escolástica realizó una jerarquización de los pecados, en la que la mayor gravedad fue otorgada al pecado contra natura, es decir, cualquier acto sexual del cual no pueda derivarse la procreación. En ese sentido, todo lo que no colaboraba con Dios en la procreación considerada "natural" -heterosexual, monogámica y matrimonial-, era considerado pecado; y por ser considerado pecado, era delito. Pero no un delito cualquiera, sino un delito que ofendía directamente a Dios, porque atentaba contra la creación y, debido a que alteraba el orden natural, merecía la pena máxima. Es así que delitos como la sodomía fueron castigados duramente. Ver para el caso argentino Fernanda Molina (2017) quien ha indagado el tratamiento judicial de los sodomitas en la sociedad colonial.
} 
Calandria, S. Nuevas figuras jurídicas, antiguas desigualdades de género: la incorporación del infanticidio en el Código Penal. Derecho y Ciencias Sociales. Mayo -Octubre 2021. N 25 .Pgs 23-44. ISSN 1852-2971. Instituto de Cultura Jurídica y Maestría en Sociología Jurídica. Facultad de Ciencias Jurídicas y Sociales. Universidad Nacional de La Plata. Argentina.

de muerte dejó de ser gradualmente utilizada para este delito cuando el asesinato del recién nacido era cometido por mujeres (Vassallo, 2006). La particularidad del perdón (o la clemencia) hacia las mujeres imputadas de matar a los recién nacidos estuvo fundado en una subestimación de sus acciones y una subordinación de su persona, acorde con el estatuto jurídico inferior con el que la definían las leyes (Hespanha, 1987). En ese sentido, al tiempo que las normativas vigentes establecían duros castigos para el asesinato de recién nacidos, se asistió a un proceso que tendió a culpabilizar a las mujeres de asesinar a los recién nacidos, especialmente a quienes habían gestado a las víctimas, al mismo tiempo que disminuyó el castigo efectivamente aplicado.

Este desplazamiento que sufrió en la praxis penal el castigo por matar a un niño/a recién nacido, comenzó a verse esbozado en la emergencia de nuevas obras influenciadas por la Ilustración, que comenzaron a ser utilizadas por los jueces para justificar sus sentencias en lugar de los textos que contemplaban las penas más duras. En ese contexto, en Argentina adquirió importancia el Diccionario de Escriche que recogió en su definición una visión atenuada del asesinato de infantes. Esta obra fue editada por primera vez en 1831, y su definición del infanticidio ya había sido tempranamente separada del parricidio, como el delito cometido por las mujer es gestantes sobre sus hijos/as, aunque el hincapié estuvo puesto principalmente en diferenciar infanticidios voluntarios e involuntarios.

Sin embargo, en 1863, se reeditó una nueva versión modificada que demostró un interés peculiar por definir al "infanticidio" como un tipo especial de delito. Esta última versión contó con un desarrollo de doce carillas para explicar qué era un infanticidio y cómo diferenciar los intencionales de aquellos que no lo eran. ${ }^{3}$ Allí, el infanticidio adquirió un tratamiento más extenso y preciso que en la anterior, dejando a la vista cómo los cambios sociales y políticos en torno a la maternidad e infancia hicieron mella en su definición jurídica:

"En la acepción más estensa de esta palabra, infanticidio es la muerte dada a un niño desde el estado de embrión hasta la pubertad, más los médicos (...) reservan el [nombre] de infanticidio para la muerte dada a un niño viable en el acto de nacer o poco tiempo después. La jurisprudencia ha debido acomodar en ese punto al lenguaje de la medicina legal; y así es que si bien en sentido lato tiene por infanticidio la muerte dada a un niño en el seno de su madre o poco después de su nacimiento, no toma en sentido riguroso esta palabra sino para denotar el homicidio

\footnotetext{
${ }^{3}$ Cabe señalar que la extensión dada al resto de los delitos contó, generalmente, con una extensión de entre 1 a 7 carillas.
} 
Calandria, S. Nuevas figuras jurídicas, antiguas desigualdades de género: la incorporación del infanticidio en el Código Penal. Derecho y Ciencias Sociales. Mayo -Octubre 2021. Nº 25 .Pgs 23-44. ISSN 1852-2971. Instituto de Cultura Jurídica y Maestría en Sociología Jurídica. Facultad de Ciencias Jurídicas y Sociales. Universidad Nacional de La Plata. Argentina.

de un niño al momento de nacer o después de nacido; y aun más propiamente, no el homicidio ejecutado en el niño por cualquier persona, sino el cometido por la madre o el padre o con su consentimiento" (Escriche, 1863: 856).

Para estos casos, en los que los culpables eran los propios padres, el jurista español argumentaba que debía establecerse la pena de muerte por parricidio, con excepción de aquellas madres solteras que cometían el hecho para ocultar su deshonra. Con esta definición, según Escriche, se daba cuenta que no existía daño social sino individual, debido a que era la madre, que se resistía a la maternidad, la única perjudicada y, citando al filósofo Jeremy Bentham (1748-1832) fundador del utilitarismo inglés, expresó:

"La pena de muerte por el infanticidio cometido por la madre (...) es la violación más manifiesta de la humanidad; porque ¿qué proporción hay entre el mal del delito y el mal de la pena? (...); y la pena es un suplicio bárbaro y afrentoso impuesto a una madre desgraciada y ciega por la desesperación, que casi a nadie ha hecho mal sino a sí misma, resistiéndose al más dulce instinto de la naturaleza” (Escriche, 1863:857).

De este modo, el Diccionario de Escriche se montaba sobre una praxis legal que ya era de hecho condescendiente con la maternidad soltera, que permitió el desplazamiento legal del significado del infanticidio durante el período previo a la codificación. Al mismo tiempo que hacía eco de las primeras manifestaciones públicas en contra de la pena capital hacia las mujeres, que provenían de las nuevas ideas penales impulsadas por la Ilustración. En ese sentido, si los Códigos, máxima aspiración ilustrada en el campo del derecho, debían limitar el arbitrio judicial estableciendo penas específicas para cada uno de los delitos a través de la letra de la ley, la definición y el castigo previsto debían plasmarse por escrito. Esta transición, que fue llamada "de justicia de jueces a justicia de leyes" (Lorente Sariñena, 2007), habilitó el debate jurídico sobre cómo castigar el infanticidio.

El infanticidio despertó los más álgidos debates en la arena pública europea sobre cómo debía castigarse este delito cuando era la madre quien lo cometía. Filósofos influyentes y representantes de estas ideas penales como Voltaire (1694-1778), Karl Hommel (1722-1781) y Cesare Beccaria (1738-1794) se opusieron a la pena capital hacia las madres solteras por infanticidio y a las leyes que asignaban un castigo a "las madres desgraciadas", proponiendo la creación de instituciones estatales de contención a la niñez desvalida para contrarrestar el 
Calandria, S. Nuevas figuras jurídicas, antiguas desigualdades de género: la incorporación del infanticidio en el Código Penal. Derecho y Ciencias Sociales. Mayo -Octubre 2021. N 25 .Pgs 23-44. ISSN 1852-2971. Instituto de Cultura Jurídica y Maestría en Sociología Jurídica. Facultad de Ciencias Jurídicas y Sociales. Universidad Nacional de La Plata. Argentina.

motivo material del infanticidio (Ulbricht, 1985). Con ello, el pensamiento ilustrado puso de manifiesto que, en muchas ocasiones, las madres solteras se veían impulsadas por la vergüenza y la pobreza, que operaban de forma tormentosa y contradictoria al momento de nacimiento de un hijo ilegítimo. Fue el reconocido e influyente penalista Beccaria uno de los primeros en diferenciar al infanticidio del resto de los homicidios y del parricidio:

"El infanticidio es igualmente efecto de una contradicción inevitable, en que se encuentra una persona que haya cedido o por violencia o por flaqueza. Quien se ve entre la infamia y la muerte de un ser incapaz de sentir los males, ¿cómo no preferirá ésta a la miseria infalible en que serían puestos ella y su infeliz parto? [...] no se puede llamar precisamente justa la pena de un delito, cuando la ley no ha procurado con diligencia el mejor remedio posible de evitarlo en las circunstancias existentes de una nación” (Beccaria, 1969: 91).

Desde esta perspectiva, la ley debía contemplar cuando las presiones sociales y económicas eran las que inducían a las madres solteras a deshacerse de los niños nacidos de una unión ilegítima, porque el hecho no nacía de su voluntad individual. De esta manera, las ideas ilustradas abrieron un debate sobre el infanticidio relacionado íntimamente a dos problemáticas sociales emergentes y características de la modernidad: la maternidad y la niñez. Uno de los primeros Códigos Penales en incorporar esta atenuación fue el Código de Baviera (1813), redactado por Paul Johann von Feuerbach (1775-1833), que distinguió al infanticidio como una figura independiente del parricidio. ${ }^{4} \mathrm{Al}$ transformarlo en un delito autónomo y eliminar la pena capital, este Código sentó un precedente en los códigos penales modernos sancionados en Europa entre 1830 y 1860. En Argentina, como señaló Thomas Duve (1999), la recepción del Código de Baviera fue limitada, pero algunas figuras penales, como el infanticidio, demostraron su influencia. ${ }^{5}$

En ese sentido, la incorporación del infanticidio a la legislación penal argentina no sólo contaba con un recorrido en la praxis judicial, sino que respondió a un problema social vernáculo que comenzó a ser visible desde mediados del siglo XIX y que se inscribió en la

\footnotetext{
${ }^{4}$ El Código de Baviera (1813) estableció en su artículo 157 que: "Sólo en el caso del nacimiento de un hijo ilegítimo, los motivos ordinarios del infanticidio, es decir, el deseo de preservar su honor, el miedo a la vergüenza pública y la perspectiva de la ruina de toda su vida actúan sobre la madre, y al combinarse con el estado de extrema excitación o el sistema nervioso de una mujer que está dando a luz, determina que el legislador no debe ser riguroso: luego se abstiene de pronunciar la pena capital contra un hecho que, sin embargo, presenta todas las características de un homicidio con premeditación".

${ }^{5}$ Entendemos la recepción jurídica no como un trasplante legal de un espacio a otro, sino como un interjuego de recepción y apropiación (Duve, 2014).
} 
Calandria, S. Nuevas figuras jurídicas, antiguas desigualdades de género: la incorporación del infanticidio en el Código Penal. Derecho y Ciencias Sociales. Mayo -Octubre 2021. Nº 25 .Pgs 23-44. ISSN 1852-2971. Instituto de Cultura Jurídica y Maestría en Sociología Jurídica. Facultad de Ciencias Jurídicas y Sociales. Universidad Nacional de La Plata. Argentina.

ideología de las clases dominantes de Argentina: la mortalidad infantil y la infancia abandonada. Tempranamente, tanto las órdenes religiosas y las organizaciones benéficas como los médicos y juristas de la época demostraron públicamente su preocupación ante la cantidad de muertes infantiles, en especial, la de bebés recién nacidos que morían, según ellos, ante las malas condiciones del parto, el desconocimiento de las madres o producto de abandonos e infanticidios. Según José Luis Moreno (2000), esta temprana sensibilidad fue prefigurativa de las incipientes políticas sociales implementadas por las organizaciones benéficas que, basadas en preceptos de la caridad cristiana, asistieron a la primera infancia. En ese sentido, en 1779, con la creación de la Casa de Niños Expósitos, el Estado comenzó a tener una intervención social más activa que se debido a la creciente preocupación por la gran cantidad de niños huérfanos, abandonados en la vía pública y muertos al nacer.

La incorporación del infanticidio como figura penal autónoma dentro del Código Penal debe ser pensada en esa clave de construcción estatal, con intenciones secularizadoras y que combinó la preocupación por la asistencia social con el disciplinamiento. En su Curso de Derecho Criminal (1860), Carlos Tejedor definió al infanticidio como un delito especial, que contemplaba un atenuante si era cometido por la madre soltera y refirió que la severidad hacia ellas había redundado en el aumento de esta práctica:

"El infanticidio es el homicidio voluntario cometido en su propio hijo. La ley romana colocaba este hecho dentro de los parricidios (...) La pena era pues la capital, ó la deportación en una isla, según calidad de la persona. Nuestras leyes no han hecho más que repetir estas disposiciones, y el resultado de tanta severidad en las penas ha sido la impunidad”. (art. 328) Luego esta estableció tres condiciones necesarias para constituirse un infanticidio: "voluntad de matar como en el homicidio, criatura nacida viva, y cierta edad en el recién nacido" (art. 329).

Es decir, aquellas madres solteras que ocultaban su embarazo para evitar la vergüenza y el estigma, por dar a luz un hijo no reconocido, debían ser castigadas por haber cometido una transgresión social y no una falta moral o un pecado. De esta manera, aunque a primera vista parezca contradictoria la disminución del castigo al infanticidio, en un contexto en el cual se empezó a expresar una preocupación política social por la infancia y la maternidad, esta afirmación adquiere sentido si se consideran que, a la vez, empiezan a percibirse otros dos fenómenos. Por un lado, que la dureza de los antiguos castigos no disminuía los índices del delito y, por el otro, que para concretar el objetivo político de consolidación del Estado, el 
Calandria, S. Nuevas figuras jurídicas, antiguas desigualdades de género: la incorporación del infanticidio en el Código Penal. Derecho y Ciencias Sociales. Mayo -Octubre 2021. N 25 .Pgs 23-44. ISSN 1852-2971. Instituto de Cultura Jurídica y Maestría en Sociología Jurídica. Facultad de Ciencias Jurídicas y Sociales. Universidad Nacional de La Plata. Argentina.

propio Estado tenía que hacerse cargo de los problemas sociales emergentes. En ese sentido, la condescendencia del castigo por infanticidio hacia las mujeres solteras debe ser enmarcada en una disputa política más amplia relacionada a la secularización social, en general, y a la del derecho, en particular.

El uso del Curso de Derecho Criminal y del Diccionario de Escriche refleja una serie de prácticas en materia penal sobre la cuestión del infanticidio, gestadas durante el período entre la Revolución de Mayo de 1810 y el proceso de codificación desde la segunda mitad del siglo en adelante. Estas prácticas fueron prefigurando una forma de abordaje particular del infanticidio, que lo escindió de su tratamiento como parricidio y que, al mismo tiempo que castigaba duramente la muerte de un infante cometida por sus progenitores, fue condescendiente con la maternidad soltera al contemplar una pena considerablemente menor para estos casos.

Nuevas figuras jurídicas, antiguas nociones de género: la incorporación del infanticidio al Código Penal Argentino

La codificación significó un punto de llegada en el proceso de centralización del poder estatal que derivó en la conformación de un nuevo orden jurídico. En Argentina, el primer intento codificador se llevó a cabo en el año 1852, cuando Justo José de Urquiza promulgó un decreto que sostenía que las leyes penales vigentes eran inaplicables debido a la crueldad, extravagancia del castigo y la arbitrariedad de jueces y magistrados (Tau Anzoátegui, 1977). La decisión de Urquiza no fue aislada, sino que representó el pensamiento de varios contemporáneos que aseguraban que la sanción de un código penal era esencial para terminar, de una vez por todas, con las viejas prácticas judiciales y, con ello, contrarrestar los poderes locales (Yangilevich, 2012).

Tras los primeros intentos fallidos, en el año 1863 el presidente del Poder Ejecutivo, Bartolomé Mitre, nombró las comisiones encargadas de redactar el proyecto de código penal que puso a cargo de Carlos Tejedor, reconocido jurisconsulto y profesor de la Cátedra de Derecho Criminal y Mercantil de la Universidad de Buenos Aires. Algunos años después, Tejedor presentó la Parte General y la Parte Especial de su proyecto, en 1865 y 1867, respectivamente ${ }^{6}$. A partir de este momento hasta que entró en vigencia el Código Penal Nacional en marzo de 1887, las provincias fueron autorizadas por el Congreso Nacional a

\footnotetext{
${ }^{6}$ Las partes General y Especial del Código Penal son divisiones que se realizaron para el estudio del derecho penal. La primera hizo referencia a las cuestiones comunes, las múltiples figuras delictivas y las normas penales. La segunda, describió específicamente los delitos y el castigo correspondientes a cada uno de ellos.
} 
Calandria, S. Nuevas figuras jurídicas, antiguas desigualdades de género: la incorporación del infanticidio en el Código Penal. Derecho y Ciencias Sociales. Mayo -Octubre 2021. N 25 .Pgs 23-44. ISSN 1852-2971. Instituto de Cultura Jurídica y Maestría en Sociología Jurídica. Facultad de Ciencias Jurídicas y Sociales. Universidad Nacional de La Plata. Argentina.

utilizar, exclusivamente dentro de sus territorios, proyectos que habían sido originalmente pensados para promulgarse como códigos nacionales (Tau Anzoátegui, 1977). La provincia de Buenos Aires adoptó el proyecto presentado por Carlos Tejedor en 1867 y diez años después, sancionó su primer código provincial. ${ }^{7}$

En ese sentido, la puesta en vigencia del nuevo Código Penal implicó, por un lado, la culminación de una etapa que había comenzado tras la Revolución de Mayo, donde el Estado había logrado el objetivo de construir un único ordenamiento jurídico en detrimento del poder de las justicias locales; ${ }^{8}$ y, por otro, el inicio de un nuevo orden legal acorde con el modelo político liberal que, con sus contradicciones, puso en marcha un nuevo sistema judicial y penal que adquirió carácter nacional, diez años después. De esta manera, el Estado se transformó efectivamente en el único garante del nuevo orden social y político, y delimitó penalmente las conductas que atentaban contra el orden social establecido.

Estudios como los de Pío Caroni (2013) cuestionaron las virtudes taumatúrgicas que convirtieron a la codificación en un símbolo de renovación radical. Según este autor, aun queriendo prescindir de los estamentos, el Código rebosó de desigualdades, es decir que su texto expresaba diferenciaciones sociales y económicas. En ese sentido, consideramos que, si bien como señalaron Carlos Garriga y José María Portillo (2012), la Ilustración impregnó el campo del derecho, lo cual es innegable en materias filosófica (de origen contractual) y técnica (cultura del código), revisitados en clave de género, sus alcances se relativizan. En ese sentido, el género se transforma en un elemento ineludible para observar la continuidad de desigualdades expresadas en los códigos legales y que, a la vez, fueron constitutivas de la sociedad moderna.

La politóloga feminista Carole Pateman (1995) manifestó que el origen contractual de la sociedad escondió relaciones de poder y dominación sobre las mujeres, quienes accedieron al espacio público de manera subordinada. El "pacto sexual", oculto tras el pacto social que dio origen a la sociedad contractual moderna, afectó la codificación en tanto aspiración jurídica igualitaria. En ese sentido, la teoría filosófica ilustrada escondió una trampa para las mujeres porque ellas no fueron incorporadas de manera igualitaria en el contrato, es decir, que no pactaron como sujetos autónomos, sino subordinadas a la autoridad de un varón en su rol de

\footnotetext{
${ }^{7}$ Matías Rosso (2016:1) indicó que todas las provincias se inclinaron por el proyecto de Tejedor, excepto Córdoba que optó por el proyecto de la comisión de 1881, redactado por Sixto Villegas, Andrés Ugarriza y Juan A. García. Por otra parte, las provincias de Jujuy y Santiago del Estero promulgaron códigos provinciales y siguieron rigiéndose por la normativa castellana hasta la sanción del primer código nacional.

${ }^{8}$ Véase: Osvaldo Barreneche (2001); Melina Yangilevich (2012); Gisela Sedeillán (2012); María Angélica Corva (2014).
} 
Calandria, S. Nuevas figuras jurídicas, antiguas desigualdades de género: la incorporación del infanticidio en el Código Penal. Derecho y Ciencias Sociales. Mayo -Octubre 2021. № 25 .Pgs 23-44. ISSN 1852-2971. Instituto de Cultura Jurídica y Maestría en Sociología Jurídica. Facultad de Ciencias Jurídicas y Sociales. Universidad Nacional de La Plata. Argentina.

padre o esposo. Adriana Valobra (2010) y Verónica Giordano (2012) señalaron, para el caso argentino, que la incapacidad civil y la exclusión política de las mujeres fueron expresiones jurídicas de las desigualdades de género.

Durante el proceso de avance estatal y constitución del derecho público y privado, el Estado fue abogando otros poderes que hasta entonces eran potestad del padre. Romina Zamora (2017), afirma que ese poder se basaba antiguamente en la noción de familia como núcleo de organización social, pero también en la autoridad incuestionable del padre de familia. Esto proviene de las antiguas definiciones del Derecho Romano, el pater era sujeto de 'sui iuris', es decir, tenía plena potestad de sí mismo y la capacidad de dominio sobre quienes no tenían ese derecho en el núcleo familiar: hijos, mujeres, ancianos, sirvientes y esclavos. A medida que se dio un proceso de secularización y se instituyera la redistribución de los poderes públicos y privados, ese espacio doméstico, antes potestad exclusiva de la autoridad del padre, comenzará a ser intervenido a través del derecho privado, entre otras instituciones. Sin embargo, al hacerlo, continuó la tradición occidental y delegó al varón (padre y esposo), la autoridad sobre la esfera doméstica.

Esta desigualdad genérica, que circunscribió a la mujer a ser esposa y madre, ya había sido regulada en la redacción originaria del Código Civil Napoleónico (1803) que fue la base de toda la legislación civil europea y latinoamericana (Giordano, 2012). La sanción de la Ley de Matrimonio, en 1888, si bien significó una expresión de la "moral moderna para sus defensores", en términos de género, expresó una clara subordinación de las mujeres a sus esposos (Giordano, 2012). Esta subordinación fue más visible y estudiada en el campo del derecho civil aunque haya atravesado también el derecho penal codificado, quizá de manera agazapada y contradictoria, mientras que el Código Civil fue más explícito, por ejemplo, porque incapacitó a las mujeres casadas y las redujo a la potestad marital mientras que el derecho penal las benefició con castigos menos severos que a los varones.

La codificación penal tuvo un lugar central dentro de los esfuerzos estatales para lograr que los individuos se ajustaran a los códigos de conducta hegemónicos de los que las propuestas ilustradas fijaron el punto de arranque del derecho liberal, convirtiendo a todo delito en una ofensa a la sociedad en su conjunto y al castigo, en una forma de defensa del contrato (Speckman Guerra, 2002). Las formas de castigar a varones y mujeres fue diferencial, pues se 
Calandria, S. Nuevas figuras jurídicas, antiguas desigualdades de género: la incorporación del infanticidio en el Código Penal. Derecho y Ciencias Sociales. Mayo -Octubre 2021. No 25 .Pgs 23-44. ISSN 1852-2971. Instituto de Cultura Jurídica y Maestría en Sociología Jurídica. Facultad de Ciencias Jurídicas y Sociales. Universidad Nacional de La Plata. Argentina.

basaban en las propias nociones del origen contractual y el libre albedrío de la escuela clásica del derecho que emergió bajo el influjo de la Ilustración. ${ }^{9}$

Según la doctrina de la escuela clásica del derecho, el hombre era capaz de actuar con libertad e inteligencia y tenía, por ende, la capacidad de escoger entre el bien y el mal. Por ello, para Tejedor, representante de esta escuela en Argentina, el castigo obtenía su legitimidad del hecho cometido y la perversidad desplegada por el agente para hacerlo, el punto de partida era que los hombres eran perfectamente capaces de comprender la criminalidad de sus actos. Sin embargo, esta fue una teoría pensada exclusivamente para varones, de la cual las mujeres fueron excluidas, al considerarse que poseían un raciocinio menor. Por esto mismo, las mujeres, las personas mayores de setenta años y las menores de 22 , fueron excluidas de la pena capital, del presidio por tiempo indeterminado y, de tratarse de una mujer honesta, se admitía su arresto domiciliario. Es así que la codificación penal tuvo un efecto paradójico para las mujeres debido a que las afectó, pero no necesariamente, las perjudicó, como lo hizo la legislación civil. Asimismo, el Código Penal de la Nación de 1886, diferenció penas y delitos según se trate de varones o de mujeres, que reforzaron los estereotipos de género.

Sin embargo, que el derecho penal excluyera a las mujeres de los castigos más hostiles, no significó que estuvieran exentas de las formas de disciplinamiento y control. Lucila Larrandart (2000) manifestó que los procesos de control social en la modernidad incluyen tanto la acción de las agencias formales especializadas, como la policía y la ley, como mecanismos de control informal y cotidianos, como la familia a través de la figura del padre /esposo. De esta manera, el nuevo orden jurídico puesto en marcha con la emergencia del Estado expresó una nueva forma de control social en clave de género que, no sólo incorporó jurídicamente a las mujeres de manera jerarquizada, sino que siguió delegando el control social de las mujeres al espacio doméstico. ${ }^{10}$ En esta disparidad, que se expresó en las formas desiguales de castigar "civilizadamente", subyació una de las formas que adquirió el control social desde la emergencia del Estado moderno: mientras que el control femenino continuó siendo territorio doméstico y, por ende, masculino; el de los varones fue únicamente potestad estatal y pública.

\footnotetext{
${ }^{9}$ La escuela clásica del derecho, continuadora de la Ilustración, postuló la doctrina del derecho natural racionalista; que el delincuente actuaba con libre albedrío; que la responsabilidad radicaba en el discernimiento, es decir, si la persona actuaba con inteligencia y libertad. Si faltaba alguno de estos requisitos desaparecía la responsabilidad por el acto (Levaggi, 2012).

${ }^{10}$ Esta nueva forma de ejercicio del poder y disciplinamiento en términos de género fue particularmente explícita en la administración de cárceles. Mientras que el Estado para garantizar el orden tomó el control y administración de las cárceles de varones, las instituciones carcelarias femeninas en todo el país fueron delegadas a la Orden del Buen Pastor. Para esto puede verse Lila Caimari (2004) y Luis González Alvo (2018).
} 
Calandria, S. Nuevas figuras jurídicas, antiguas desigualdades de género: la incorporación del infanticidio en el Código Penal. Derecho y Ciencias Sociales. Mayo -Octubre 2021. Nº 25 .Pgs 23-44. ISSN 1852-2971. Instituto de Cultura Jurídica y Maestría en Sociología Jurídica. Facultad de Ciencias Jurídicas y Sociales. Universidad Nacional de La Plata. Argentina.

Así como el establecimiento de penas menos severas para las mujeres reforzó la subordinación femenina, la exaltación del rol doméstico y maternal impactó en las matrices de tipificación de los delitos. Como señaló Marcela Nari (2004), a fines del siglo XIX, la exaltación de la maternidad incluyó una serie de procesos biológicos tales como la fecundación, el embarazo y el parto, que se extendieron hasta alcanzar prácticas y relaciones sociales que no han estado vinculadas fisiológicamente al cuerpo femenino como el cuidado, la crianza y el cariño. Sobre esta base, el Código Penal constituyó delitos considerados "típicos" de las mujeres, cuyo fundamento se sedimentó en ciertos elementos como la debilidad y el sentimentalismo percibidos como "naturalmente femeninos". Estos delitos considerados femeninos se relacionaron, especialmente, con las prácticas antireproductivas que ponían en cuestión el binomio madre-hijo: el aborto, el abandono de niños y el infanticidio. De igual forma, castigó a las mujeres adúlteras más duramente que a los varones que cometían el mismo delito dejando entrever la "doble moral" con la que varones y mujeres fueron juzgados (Giordano, 2014). Esta diferenciación, apuntó a normar a las mujeres a las pautas de convivencia familiar a través de la regulación de las relaciones íntimas y la reproducción legítima, según el modelo de familia patriarcal.

Las modificaciones que sufrió la tipificación del infanticidio durante la codificación penal fueron una expresión de esa transformación del orden jurídico en términos de género y deben ser leídas en esa clave. Al hacer una lectura del texto legal en clave de género podemos dimensionar mejor como este modelo familiar justificaba las diferenciaciones que aparecen en el Código Penal. El Código Penal de la Nación estableció en sus artículos 100 y 101 cuales eran las conductas, bajo qué motivaciones y quiénes debían desplegarlas para incurrir en infanticidio:

"La madre que por ocultar su deshonra cometiese infanticidio sobre la persona de su hijo, en el momento de su nacimiento o hasta tres días después, y los abuelos maternos, que por ocultar la deshonra de la madre, cometiesen el mismo delito, serán castigados con la pena de penitenciaria por tres á seis años. Fuera de estos casos, el que cometa infanticidio, será castigado con la pena del homicidio".

Es decir, que para aquellos casos en los que no se podía comprobar que la mujer había actuado para ocultar su deshonra, el recién nacido tenía más de tres días o el hecho había sido cometido por algún familiar que no fuera alguno de los abuelos maternos, el delito era considerado un homicidio agravado por el vínculo y regía el artículo 94 del Código: 
Calandria, S. Nuevas figuras jurídicas, antiguas desigualdades de género: la incorporación del infanticidio en el Código Penal. Derecho y Ciencias Sociales. Mayo -Octubre 2021. Nº 25 .Pgs 23-44. ISSN 1852-2971. Instituto de Cultura Jurídica y Maestría en Sociología Jurídica. Facultad de Ciencias Jurídicas y Sociales. Universidad Nacional de La Plata. Argentina.

"El que a sabiendas mata a su padre, madre o hijo legítimo o natural, o a cualquier otro ascendiente, descendiente o a su cónyuge, será castigado: con la pena de muerte si no ocurre atenuante alguno o con presidio por tiempo indeterminado si existiese una o más circunstancias atenuantes".

La diferencia en el monto de castigo establecido para cada figura fue abismal. Para que un hecho pueda tipificarse como infanticidio, según Tejedor, debía existir tres requisitos: 1- que la criatura nazca viva; 2- que el recién nacido no tenga más de tres días; 3- que exista voluntad de matar, radicada en la intención de la madre o familiares maternos en ocultar la deshonra (Tejedor, 1860). Los primeros dos elementos fueron progresivamente convirtiéndose en territorio de la medicina legal que, como se profundizará en el apartado siguiente, tuvo un rol clave en la comprobación del hecho y sus diagnósticos fueron insoslayables para la elaboración de las estrategias de los defensores y fallos de los jueces. Mientras el segundo, ligado a la honra, elemento central de la figura de infanticidio, estableció una clara diferenciación entre quiénes accedían a ese "beneficio" y quiénes no. Este beneficio penal se basaba en el supuesto peso social y las consecuencias en la honra de la familia, que podía tener el nacimiento de un hijo ilegítimo. En ese sentido, el móvil del delito debía ser únicamente el ocultamiento de la deshonra, pero el Código, al considerar que la honra podía modificar la penalidad de un homicidio y establecer una consideración para la madre soltera, reforzó roles y tipificó conductas diferenciadas para varones y mujeres.

El tratamiento diferenciado no radicaba únicamente entre varones y mujeres, su tipificación también separaba entre la maternidad "legítima" y la "ilegítima". Con esto nos referimos a la diferenciación establecida en el Código Civil sobre la condición de los hijos que habían nacido fuera o dentro de un matrimonio civil. En ese sentido, el Código establecía que sólo cuando la mujer gestante daba a luz un hijo ilegítimo podía calificarse como un infanticidio. Sin embargo, excluyó a las mujeres casadas, debido a que consideró que en ese caso no había motivo alguno para cometer el delito; es más, era inconcebible que en esa situación quisieran deshacerse de un hijo, naturalizando su rol maternal. Esto demuestra que, aunque los nacimientos ilegítimos eran frecuentes entre los sectores populares de la población argentina (Bjerg y Otero, 2006), siguieron siendo un elemento diferenciador en el campo del derecho y en la sociedad misma. Isabella Cosse (2008) señaló que la maternidad soltera era concebida una desviación, pues el vínculo matrimonial consolidaba las expectativas sociales respecto a los roles de género asignados tanto a los varones como a las mujeres. De este modo, 
Calandria, S. Nuevas figuras jurídicas, antiguas desigualdades de género: la incorporación del infanticidio en el Código Penal. Derecho y Ciencias Sociales. Mayo -Octubre 2021. Nº 25 .Pgs 23-44. ISSN 1852-2971. Instituto de Cultura Jurídica y Maestría en Sociología Jurídica. Facultad de Ciencias Jurídicas y Sociales. Universidad Nacional de La Plata. Argentina.

la dicotomía legitimidad-ilegitimidad jurídica del nacimiento se constituyó como un factor divisorio fundamental en la aplicación de la figura de infanticidio y su incorporación al Código legitimó la división entre maternidades honrosas y vergonzosas, de las que se hacía eco la sociedad.

Como manifestó Suann Caulfield (2000), la honra se transformó en uno de los principales fundamentos de la autoridad patriarcal moderna, permitiendo la preservación de la dominación masculina y el control de la sexualidad femenina. Ahora bien, consideramos que esta forma de dominación patriarcal fue posible debido a la capacidad que tuvo el Código Penal de establecer un doble movimiento que tomó los conceptos de honra y deshonra para definir al infanticidio pero haciendo omisión sobre a qué se refería con eso. Pío Caroni (2013: 48) señaló que el Código "no registra las desigualdades, no habla de ellas explícitamente, se comporta como si no existiesen o fuesen insignificantes" y que, justamente, es en esta abstracción donde radica una forma de violencia que se aviene perfectamente a la función normativa desarrollada por el derecho". El legislador, al crear una figura como el infanticidio e incorporar dentro del móvil del acto de matar al hijo el evitar la deshonra de las mujeres, registraba un concepto al que, al mismo tiempo, se abstenía de definir, legitimando una forma de violencia de tipo patriarcal que fue parte insoslayable en su constitución.

Al nombrar la deshonra sin describirla, la figura de infanticidio habilitó una serie de tensiones con relación a lo que significaba la honra femenina. Estos debates transcendieron la arena "técnica" del derecho y se situaron claramente en el campo de los valores y la moral debido a que la posesión o pérdida de la honra se relacionó con el comportamiento sexual y el recato público. De tal manera, aunque no estuviera referido en la norma, la doctrina consideró que para que fuera aplicable el atenuante o móvil, las mujeres debían comprobar su honorabilidad. Al respecto, Joaquín Escriche (1863: 857) expresó que:

"Cuando la infanticida es una mujer de corrompidas costumbres o de mala fama anterior, cuando no comete el crimen sino por desembarazarse de una carga o por aversión a su marido o por soborno o por torcido fin, cuando teniendo medios lícitos de cubrir el olvido de sí misma prefiere el sacrificio sangriento del fruto de su extraviado amor, cuando no siendo la primera vez que ha incurrido en un atentado de esta especie, muestra bastante con su reincidencia que abriga en su pecho un corazón depravado; el rigor de la ley debe caer sobre su cabeza, y venir a proteger a esos seres desvalidos que produce la desmoralización para lanzarlos desde el seno materno en el sepulcro". 
Calandria, S. Nuevas figuras jurídicas, antiguas desigualdades de género: la incorporación del infanticidio en el Código Penal. Derecho y Ciencias Sociales. Mayo -Octubre 2021. Nº 25 .Pgs 23-44. ISSN 1852-2971. Instituto de Cultura Jurídica y Maestría en Sociología Jurídica. Facultad de Ciencias Jurídicas y Sociales. Universidad Nacional de La Plata. Argentina.

Esto significaba que las mujeres que ejercían la prostitución o quienes habían tenido un hijo ilegítimo previamente, quedaban excluidas de esta tipificación. Sin embargo, la definición de "mujer de corrompidas costumbres o de mala fama anterior" se tornaba aún más ambigua por fuera de estos dos casos puntuales. Este concepto, vacío a nivel legislativo pero cargado de significado a nivel social, habilitó una serie de discusiones con relación al comportamiento sexual femenino, ligadas a la virginidad, recato sexual y maternidad, que reforzaron la ideología de la domesticidad y de la subordinación femenina al mandato patriarcal.

Si bien como indicó Michel Foucault (1990), la principal transformación introducida por Ilustración al orden judicial y penal radicó en considerar que el crimen o infracción penal era la ruptura con pacto social, esta consideración no estuvo exenta de las desigualdades de género porque se suponía que la transgresión femenina no se realizaba con el mismo raciocinio que la transgresión masculina y, por ende, el castigo debía aplicarse de forma diferencial.

En síntesis, en la figura de infanticidio incorporada al Código Penal como una excepcionalidad de los principios reguladores del castigo del derecho Ilustrado, y que fundaba una disminución de la pena por la condición de ser la autora del delito, se hallaron agazapadas antiguas nociones de género. Estas continuidades con el Antiguo Régimen se pusieron en evidencia en la interpretación que los jueces hicieron del concepto de la honra femenina, que no estaba definido por la ley y daba lugar a un amplio campo de discrecionalidad judicial que habilitó que se pusieran en juego concepciones ligadas al recato sexual femenino heredado de la moral cristiana. De tal forma, el nuevo código asumía, sin hacerlo explícito, valores propios del orden jurídico con el que se quería acabar. De esta manera, al mismo tiempo que la codificación intentó despojar al delito de sus antiguas connotaciones acerca de la transgresión moral y del pecado, en estas diferenciaciones entre mujeres deshonestas y honestas, destinó la mayor severidad para aquellas mujeres “desviadas” de los cánones de maternidad y femineidad.

\section{Reflexiones finales}

La Ilustración introdujo cambios sociales y políticos que reverberaron en el campo del derecho, el más representativo de ellos fue el de la codificación. Al codificar, los legisladores y juristas recogieron prácticas e ideas filosóficas con relación al infanticidio que terminaron por constituirlo como una figura penal autónoma del parricidio. En este sentido, cuando las leyes comenzaron a regular la impartición de justicia y el Código se instituyó como la única fuente 
Calandria, S. Nuevas figuras jurídicas, antiguas desigualdades de género: la incorporación del infanticidio en el Código Penal. Derecho y Ciencias Sociales. Mayo -Octubre 2021. Nº 25 .Pgs 23-44. ISSN 1852-2971. Instituto de Cultura Jurídica y Maestría en Sociología Jurídica. Facultad de Ciencias Jurídicas y Sociales. Universidad Nacional de La Plata. Argentina.

del derecho donde estaban delimitados claramente cada uno de los delitos y sus penas, se constituyó una excepción que distinguió al infanticidio del resto de los homicidios, producto de un cambio histórico en la interpretación de esta práctica.

Esta figura, al mismo tiempo que recogía una praxis jurídica propia del sistema penal anterior, legitimaba un tipo de castigo para la madre soltera que fue producto de la "maternalización" del infanticidio, es decir un proceso sociohistórico que culpabilizó a las mujeres como las únicas posibles perpetradoras de este delito. Pero que, a su vez, constituyó un tipo penal para atenuar el hecho cuando era cometido por la mujer gestante para ocultar su deshonra y los abuelos maternos con el mismo objetivo. En ese sentido, la adopción del infanticidio como un artículo del Código, respondió a una coyuntura particular de construcción del Estado en donde las problemáticas sociales y sus formas de abordaje tuvieron un peso muy particular, configurando el desarrollo de un Estado que, a fines del siglo XIX, combinó dos estrategias concomitantes: disciplinamiento y asistencia (Moreno, 2000).

Esta excepción en el castigo de las madres solteras recogía y reforzaba una vieja noción que presuponía que la posibilidad de perder la honra generada por el embarazo ilegítimo podía impulsar a las madres a deshacerse de sus hijo para no cargar con las consecuencias derivadas de la vergüenza social. De este modo, la honra de la madre soltera se transformó en un concepto clave para la definición legal del infanticidio, al punto de que otros elementos como el honor vincular y los días de vida del recién nacido se tornaron secundarios en esta definición. En ese sentido, el fundamento original de la creación de su figura se mantuvo como un pilar hasta su derogación del Código Penal en el año 1994 (ley 24.410). Aunque también se incluyeron con el tiempo otros elementos que se consideraron representantes de la emergencia de la penalidad moderna, como el estado puerperal y la emoción violenta, no pudieron desplazar a la honra como su móvil principal.

Sin embargo, esta condescendencia respecto de la honra femenina con relación a la maternidad soltera encubrió una desigualdad de género propia de la sociedad colonial pero que, a su vez, fue constitutiva de la penalidad moderna. Consideramos que en las pretensiones de “modernizar" el derecho a través de una nueva concepción filosófica y técnica, subyacieron antiguas nociones de género vinculadas a la sexualidad pecaminosa, la moralidad y el recato femenino propias de la sociedad colonial que se asentaron y reforzaron la subordinación femenina en el orden patriarcal moderno. Es decir, cuando el infanticidio fue creado como figura autónoma, al contemplar la honra como móvil del delito, la legislación incorporó un 
Calandria, S. Nuevas figuras jurídicas, antiguas desigualdades de género: la incorporación del infanticidio en el Código Penal. Derecho y Ciencias Sociales. Mayo -Octubre 2021. N 25 .Pgs 23-44. ISSN 1852-2971. Instituto de Cultura Jurídica y Maestría en Sociología Jurídica. Facultad de Ciencias Jurídicas y Sociales. Universidad Nacional de La Plata. Argentina.

atenuante para las madres solteras pero, al mismo tiempo, se estructuró sobre desigualdades de género y estereotipos basados en la sexualidad femenina.

El afán de modernizar el sistema penal no excluyó antiguas nociones de género que, a través de conceptos como la honra y deshonra femeninas, fueron incorporados al Código reforzando las desigualdades de género en un contexto donde se pretendía abolir con las jerarquías sociales. En ese sentido, como diría Pateman (1995), lo "moderno" del contrato jurídico se montaba sobre un contrato sexual inescrutable previo al momento de codificación.

\section{Bibliografía}

Agüero, A. (2008). Castigar y perdonar cuando conviene a la república: La justicia penal de Córdoba de Tucumán, siglos XVII y XVIII. Madrid: Centro de Estudios Políticos y Constitucionales.

Barreneche, O. (2001). Dentro de la ley, todo: La justicia criminal de Buenos Aires en la etapa formativa del sistema penal moderno de la Argentina. Buenos Aires: Ediciones al Margen.

Beccaria, C. (1969). De los delito y las penas. Madrid: Aguilar.

Bjerg, M., \& Otero, H. (Eds.). (2006). Inmigración, liderazgos étnicos y participación política en comunidades rurales. Buenos Aires: Biblos.

Bourdieu, P. (1986). The force of law: Toward a sociology of the juridical field. Hastings Law Journal, 38, 814-853.

Caimari, L. (2007). Entre la celda y el hogar. Dilemas estatales del castigo femenino (Buenos Aires, 1890-1940). Nueva Doctrina Penal. Recuperado de https://www.academia.edu/4121399/Entre_la_celda_y_el_hogar._Dilemas_estatales_del _castigo_femenino_Buenos_Aires_1890-1940

Calandria, S. (2018). Resquicios jurídicos en el discurso del poder: Honra y moralidad sexual en los fallos de infanticidio (provincia de Buenos Aires, 1887-1921). Historia y Justicia, (11), 14-41.

Calandria, S. (2019). Cómplices y verdugos: Masculinidades, género y clase en los delitos de infanticidio (provincia de Buenos Aires, 1886-1921). História (São Paulo), 38, e2019045.

Calandria, S., \& Ledesma Prietto, N. (2018). Abortos e Infanticidios: Tensiones y debates en la legislación penal moderna (1886-1968). Avances del Cesor, 15(19), 101-128. 
Calandria, S. Nuevas figuras jurídicas, antiguas desigualdades de género: la incorporación del infanticidio en el Código Penal. Derecho y Ciencias Sociales. Mayo -Octubre 2021. Nº 25 .Pgs 23-44. ISSN 1852-2971. Instituto de Cultura Jurídica y Maestría en Sociología Jurídica. Facultad de Ciencias Jurídicas y Sociales. Universidad Nacional de La Plata. Argentina.

Caroni, P. (2013). Lecciones de historia de la codificación. Madrid: Universidad Carlos III de Madrid; Dykinson.

Cartelle, E. M. (2010). La sexualidad medieval en sus manifestaciones lingüísticas: Pecado, delito y algo más. Clío \& Crímen: Revista del Centro de Historia del Crimen de Durango, 7,41 .

Caulfield, S. (2000). Em defesa da honra: Moralidade, modernidade e naçäo no Rio de Janeiro (1918-1940). Campinas: Editora UNICAMP.

Código Penal (1887). Zaffaroni, E. R. y Arnedo, M. A(1996). Digesto de codificación penal argentina. Buenos Aires: A/Z editora.

Código Penal (1922). Zaffaroni, E. R. y Arnedo, M. A(1996). Digesto de codificación penal argentina. Buenos Aires: A/Z editora.

Corva, M. A. (2014). Constituir el gobierno, afianzar la justicia: El Poder Judicial de la provincia de Buenos Aires. Rosario: Prohistoria.

Cosse, I. (2004). Entre el estigma y la integración. Imágenes, estereotipos y representaciones de la filiación ilegítima en Argentina (1940-1955). En H. Otero (Ed.), El mosaico argentino. Modelos y representaciones del espacio y la población. Buenos Aires: Siglo XXI.

Di Corleto, J. (2018). Malas madres. Aborto e infanticidio en perspectiva histórica. Buenos Aires: Didot.

Duve, T. (1999). ¿Del Absolutismo Ilustrado al Liberalismo Reformista? La recepción del Código Penal bávaro de 1813 de PJA von Feuerbach en Argentina y el debate sobre la reforma del derecho penal hasta 1921. Revista de Historia del Derecho, (27), 125-152.

Duve, T. (ed.) (2014), Entanglements in Legal History: Conceptual Approaches, Global Perspectives on Legal History, Max Planck Institute for European Legal History Open Access Publication, Frankfurt am Main, http://dx.doi.org/10.12946/gplh1

El Sabio Alfonso, X. (2004). Las siete partidas. El Cid Editor.

Escriche, J. (1852). Diccionario razonado de legislación y jurisprudencia. París: Librería de Rosa, Bouret y cia.

Foucault, M. (1990). La verdad y las formas jurídicas. México: Gedisa Mexicana.

Garriga, C., \& Portillo, J. M. (2012). La ilustración jurídica. En M. Valencia \& Vallejo, Manual de historia del derecho (pp. 259-288).

Giordano, V. (2012). Ciudadanas incapaces: La construcción de los derechos civiles de las mujeres en Argentina, Brasil, Chile y Uruguay en el siglo XX. Buenos Aires: Teseo. 
Calandria, S. Nuevas figuras jurídicas, antiguas desigualdades de género: la incorporación del infanticidio en el Código Penal. Derecho y Ciencias Sociales. Mayo -Octubre 2021. № 25 .Pgs 23-44. ISSN 1852-2971. Instituto de Cultura Jurídica y Maestría en Sociología Jurídica. Facultad de Ciencias Jurídicas y Sociales. Universidad Nacional de La Plata. Argentina.

González Alvo, L. (2018). El Tiempo de la Prisión. La reforma penitenciaria en Córdoba, Santa Fé y Tucumán (1853-1946). Universidad Nacional de La Plata. Facultad de Humanidades y Ciencias de la Educación, La Plata.

Hespanha, A. M. (1993). La gracia del derecho: Economía de la cultua en la edad moderna. Madrid: Centro de Estudios Constitucionales.

Hespanha, A. M. (1987). Da «iustitia» à «disciplina», textos, poder e política penal no antigo regime. Anuario de historia del derecho español, 57, 493-578.

Juliano, D. (2009). Delito y pecado. La transgresión en femenino. Política y Sociedad, 46(1/2), 79-95

Larrandart, L. (2000). Control social, derecho penal y género. En H. Birgin (Ed.), El género del derecho penal: Las trampas del poder punitivo. Buenos Aires: Biblos.

Levaggi, A. (2012). El derecho penal argentino en la historia. Buenos Aires: Eudeba.

Lorente Sariñena, M. (2007). De justicia de jueces a justicia de leyes: Hacia la España de 1870.

Madrid: Consejo General del Poder Judicial, Centro de Documentación Judicial.

Lorente Sariñena, M., \& Vallejo, J. (2012). Manual de Historia del Derecho. Madrid: Tirant lo Blanch.

Molina, F. (2017). Cuando amar era pecado. Sexualidad, poder e identidad entre los sodomitas coloniales (Virreinato del Perú, siglos XVI-XVII). Lima: FEA, Plural editores.

Moreno, J. L. (2000). La política social antes de la política social. Caridad, beneficencia y política social en Buenos Aires (siglos XVII a XX). Trama editorial/Prometeo libros.

Nari, M. (2004). Políticas de maternidad y maternalismo político: Buenos Aires, 1890-1940. Buenos Aires: Biblos

Pateman, C. (1995). El contrato sexual. Madrid: Anthropos

Piazzi, C. (2009). Homicidios de niños: Legislación, honor y vínculos entrañables.(Rosario, segunda mitad del siglo XIX). Horizontes y Convergencias, 165-189.

Prósperi, A. (2016). Infanticide, Secular Justice, and Religious Debate in Early Modern Europe. Brepols, 20, 142-146.

Rosso, M. (2016). Codificación Penal Provincial. Aplicación del Código Penal en la Provincia de Córdoba (1883-1886). Revista Prólogos, VIII, 55-80.

Ruggiero, K. (1994). Honor, maternidad y el disciplinamiento de las mujeres: Infanticidio en el Buenos Aires de finales del siglo XIX. En L. Fletcher (Ed.), Mujeres y cultura en la Argentina del siglo XIX. Buenos Aires: Feminaria Editora. 
Calandria, S. Nuevas figuras jurídicas, antiguas desigualdades de género: la incorporación del infanticidio en el Código Penal. Derecho y Ciencias Sociales. Mayo -Octubre 2021. № 25 .Pgs 23-44. ISSN 1852-2971. Instituto de Cultura Jurídica y Maestría en Sociología Jurídica. Facultad de Ciencias Jurídicas y Sociales. Universidad Nacional de La Plata. Argentina.

Sedeillán, G. (2012). La justicia penal en la provincia de Buenos Aires: Instituciones, prácticas y codificación del derecho (1877-1906). Buenos Aires: Editorial Biblos.

Speckman Guerra, E. (2002). Crimen y castigo: Legislación penal, interpretaciones de la criminalidad y administración de justicia, Ciudad de México, 1872-1910 (1. ed). México, D.F: El Colegio de México: Universidad Nacional Autónoma de México.

Tau Anzoátegui, V. (1977). La codificación en la Argentina (1810-1870): Mentalidad social e ideas jurídicas (Vol. 11). Imprenta de la Universidad.

Tejedor, C. (1871). Curso de derecho criminal. Buenos Aires: Librería de Cl. M. Joly.

Ulbricht, O. (2015). Infanticide in eighteenth-century Germany. En R. Evans (Ed.), The German Underworld. Deviants and Outcasts in German History (pp. 124-156). Londres: Routledge

Valobra, A. (2010). Del hogar a las urnas. Recorridos de la ciudadanía política femenina Argentina, 1946-1955. Rosario: Prohistoria Ediciones.

Vassallo, J. (2006). Mujeres delincuentes: Una mirada de género en la Córdoba del siglo XVIII. Córdoba: Centro de Estudios Avanzados, Universidad Nacional de Córdoba.

Vatel, C. (1852). Code Pénal pour le Royaume de Bavière traduit de l'allemand avec des explications tirées du Commentaire Officiel (Exposé de Motifs) et un appendice. París.

Yangilevich, M. (2012). Estado y criminalidad en la frontera sur de Buenos Aires (1850-1880). Rosario: Prohistoria.

Zamora, R. (2017). Casa poblada y buen gobierno. Oeconomia catolica y servicio personal en Tucuman, Siglo XVIII. Buenos Aires: Prometeo Libros. 